\title{
Variation of chemical composition with age in human femoral head cartilage
}

\author{
M. F. VENN
}

From the Bone and Joint Research Unit, London Hospital Medical College, Arthritis and Rheumatism Counce Building, 25 Ashfield Street, London E1 2 AD

SUMMARY The chemical composition of intact femoral head cartilage was investigated with age Full-depth cartilage showed a decrease in water content and an increase in keratan sulphate an noncollagenous material with age. When analysed through the depth of the cartilage, keratan sulphate was shown to appear first in the deep zones and later in the surface, while water conterip was lost mainly in the deep zones. On a dry weight basis collagen content decreased with age. Th $\overrightarrow{8}$ was not a real loss but was due to a change in the proportions of other materials, mainly in the deep zones.

There is little evidence from early studies on adult articular cartilage for any major quantitative variations of cartilage composition with age. For example, Bollet and Nance (1966) found no change with age in the chondroitin sulphate or neutral sugar content, in chondroitin sulphate chain length, or in the water or ash content of normal cartilage from the human femoral condyle. Similar results were reported by Anderson et al. (1964) and Miles and Eichelberger (1964). In femoral head and femoral condyle cartilage a decrease in water content and increase in total glycosaminoglycan content with age was noted, but this was not statistically significant (Maroudas et al., 1973).

Although the total glycosaminoglycan content may show little age variation, the keratan to chondroitin sulphate ratio is well known to change with age. For example, in the adult human knee joint Hjertquist and Lemperg (1972) showed an increasing ratio of keratan sulphate plus glycoproteins to chondroitin sulphate with age. This agrees with the earlier findings of Kuhn and Leppelmann (1957) for articular cartilage, and of Kaplan and Meyer (1959) for costal cartilage. Other changes with age include a decrease in chondroitin sulphate chain length (Hjertquist and Wasteson, 1972) and an increase in sialic acid content (Strider et al., 1976).

Adult articular cartilage shows an increase in degenerative changes with age (Collins and Meachim, 1961). Cartilage composition also varies from joint

Accepted for publication July 25, 1977

Correspondence to Dr M. Venn, c/o Dr S. J. Walter, Physiology Department, Charing Cross Hospital, Fulham Palace Road, London W6 to joint (e.g. Maroudas, 1975) and with topography on a single joint (Bjelle, 1974; M. Venn, unpublished results). Selecting nondegenerate cartilage from. single area from a specific joint has reduced th variation between samples sufficiently to recognises age-related biochemical changes. For examplo, Ruttner et al. (1974) showed a decrease in water content with age in the pressure areas of the huma femoral head, while the glycosaminoglycan conte showed little variation after maturity. Collage content on a dry basis showed a surprising decrease with increasing age (Werner et al., 1976).

Age-related changes are also known to occur wi depth from the articular surface. For example, Stockwell (1970) showed biochemically and hist logically a large increase in keratan sulphate content in the deep zone of femoral condylar cartilage in the third decade, which reached a plateau at the end of the fourth decade. There was little change in to uronic acid content after maturity. Variation is composition with depth at different ages was alse noted in bovine cartilage by Lemperg et al. (1970 1974). They found a significant decrease in water content with distance from the articular surface $\mathbb{M}^{\mathrm{B}}$ all age groups; water content was lower in heife than in calf cartilage but showed an increase in the adult. Keratan sulphate showed an increase depth from the surface only in the older age groups.

The aim of the present study was to make :a comprehensive survey of the changes with age in the gross constituents of cartilage (collagen, water, and glycosaminoglycans), both in full thickness specime@ and with depth from the articular surface. Throug $\mathbb{B}$ out this study intact cartilage from the superier 
region of the femoral head was used, in order to ensure that no degenerative changes were included. Fibrillation may be regarded as a separate agerelated phenomenon (Freeman and Meachim, 1973). In the femoral head early stages of fibrillation are noted at the periphery and below the fovea (Byers et al., 1970) and the area of cartilage showing degeneration increases with age.

\section{Materials}

Human femoral heads with an age range of 3 to 86 years were obtained at post mortem and stored at $-20^{\circ} \mathrm{C}$ until use. Two adjacent full depth plugs of cartilage $(1 \mathrm{~cm}$ diameter) were excised from the superior region of each femoral head. Specimens which showed any surface defect or which stained with Indian ink were rejected. To give an indication of the changes in chemical composition with depth, one chunk from each pair was sliced into $200 \mu \mathrm{m}$ slices parallel to the articular surfaces using a freezing microtome. The other specimen was analysed intact. Mean values were obtained for the variation of cartilage composition with depth for four age ranges: 14 to $29(n=6$; mean age 17 years, range $14-23)$; 30 to $49(n=5$; mean age 41 , range $32-49)$; 50 to $69(\mathrm{n}=8$; mean age 63 , range $51-69)$; and 70 to $90(n=6$; mean age 80 , range $73-90)$.

\section{Methods}

Cartilage thickness was measured using a millimeter micrometer. Fixed charge density was measured by the tracer cation method as previously described (Maroudas and Thomas, 1970). The wet weight of each specimen was determined after soaking in $0.15 \mathrm{M} \mathrm{NaCl}$. The dry weight was determined by drying to constant weight at $67^{\circ} \mathrm{C}$.

Cartilage samples were digested in papain solution $\left(1 \mathrm{ml} / 20 \mathrm{mg}\right.$ dry weight) overnight at $67^{\circ} \mathrm{C}$ (Hjertquist and Lemperg, 1967). The digests were diluted and duplicate samples taken for chemical analysis. The uronic acid content was estimated by an automated version (von Berlepsch, 1969) of the Bitter and Muir (1962) procedure. Hexosamine content was determined by the Elson and Morgan (1933) reaction. Hydroxyproline was determined by the Stegemann method (1958) as modified for automated analysis by Grant (1964).

\section{Calculations}

Collagen content was calculated by multiplying the hydroxyproline results by a factor of $7 \cdot 6$. Chondroitin sulphate content was estimated from the uronic acid content $(\mathrm{mmol} / \mathrm{g})$ and expressed as a percentage of the wet or dry weight by multiplying by a factor of 513 (the molecular weight of the disaccharide). Keratan sulphate was estimated by subtracting the uronic from the hexosamine content $(\mathrm{mmol} / \mathrm{g})$ and the total calculated by multiplying by 464 .

\section{Results}

AGE-RELATED CHANGES IN FULL THICKNESS CARTILAGE

Cartilage thickness was greatest in young tissue and decreased rapidly in the early years but showed little change after maturity (Fig. 1). The water content of cartilage showed a linear decrease with age (Fig. 2).

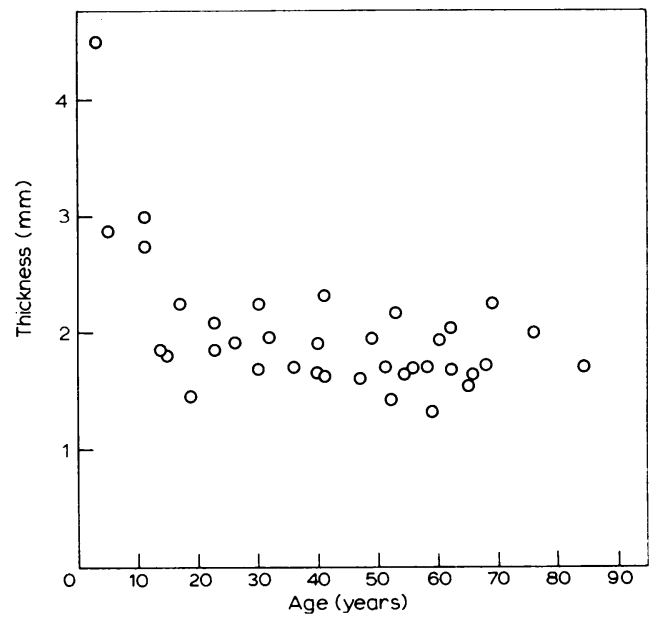

Fig. 1 Variation of cartilage thickness with age in human femoral head.

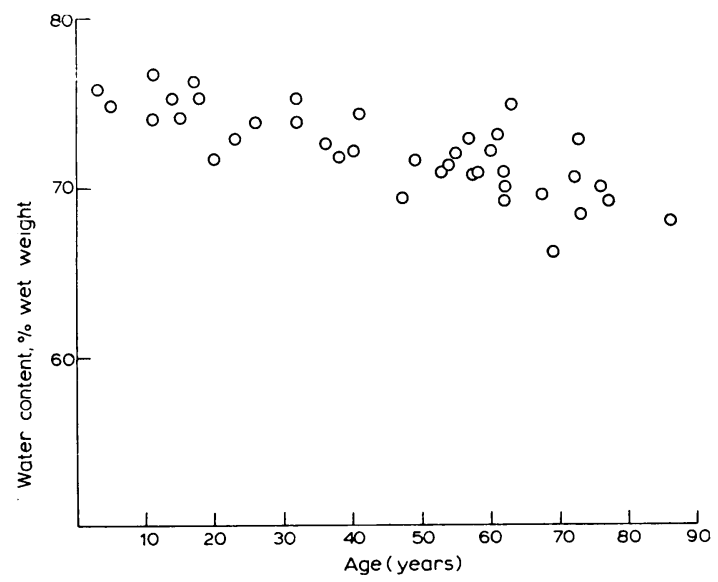

Fig. 2 Variation of water content with age in full depth cartilage. 
On a wet weight basis the fixed charge density method increased with age. This increase mainly took place in the age group up to $\mathbf{4 0}$ years (Fig. 3). Chondroitin sulphate content showed no age dependence, thus an increase in keratan sulphate content was responsible for the increase in fixed charge density (Fig. 3). On a dry weight basis there was no change in total glycosaminoglycan content after maturity. Collagen content showed no age dependence on a wet weight basis, but decreased with increasing age on a dry basis (Fig. 4). This was

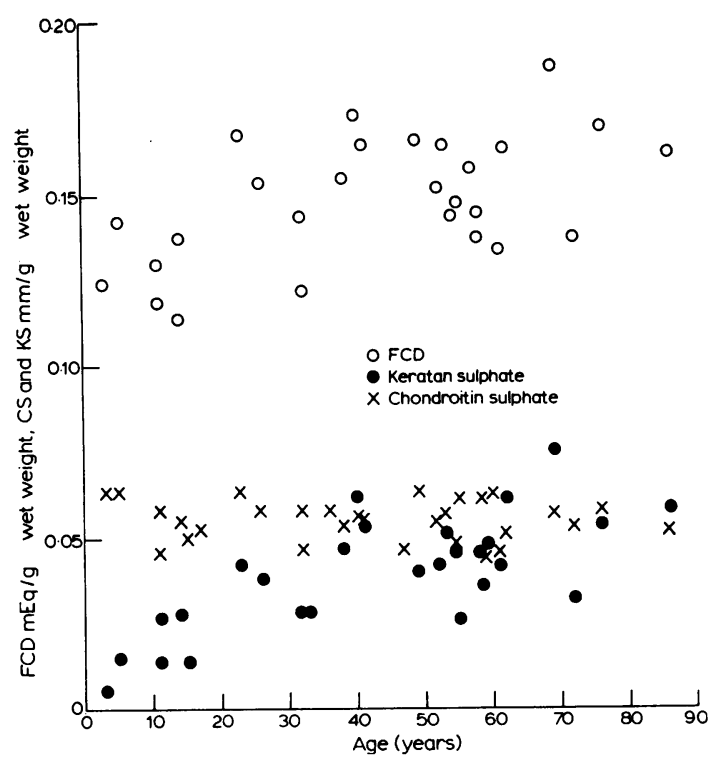

Fig. 3 Variation of fixed charge density (FCD), keratan and chondroitin sulphate content with age.

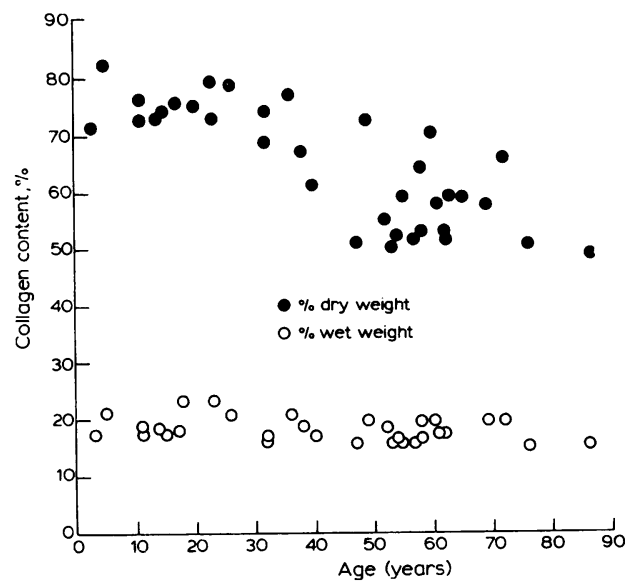

Fig. 4 Variation of collagen content on $a$ wet and dry weight basis with age. probably due to an increase in mineral and/or none collagenous protein, since the percentage of the dre? weight accounted for by collagen and total glyco saminoglycans decreased with age (Fig. 5).

\section{AGE-RELATED CHANGES WITH DEPTH}

Mean values were obtained for the variation composition with depth in four age ranges (14-29 $30-49 ; 50-69 ; 70-90$ years). The profile for variation of water content with depth was grossly similar $\$$ all ages, hydration being greatest at the surface and decreasing to a minimum in the deeper zones (Fig. $6 \%$ However, with increasing age water content was

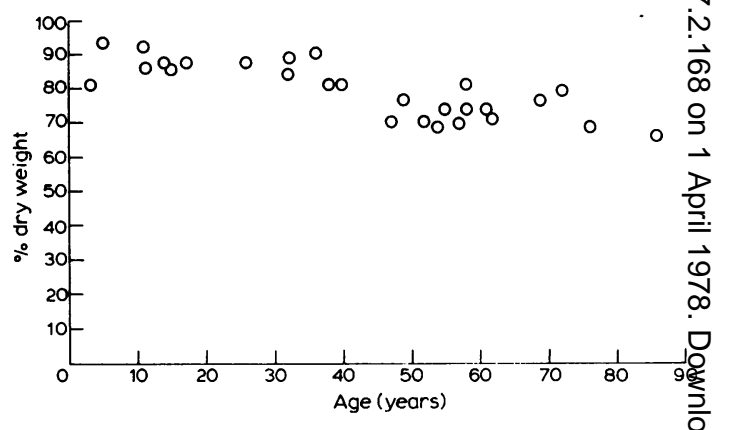

Fig. 5 Percentage of the dry weight accounted for by collagen, and chondroitin and keratan sulphate with age.

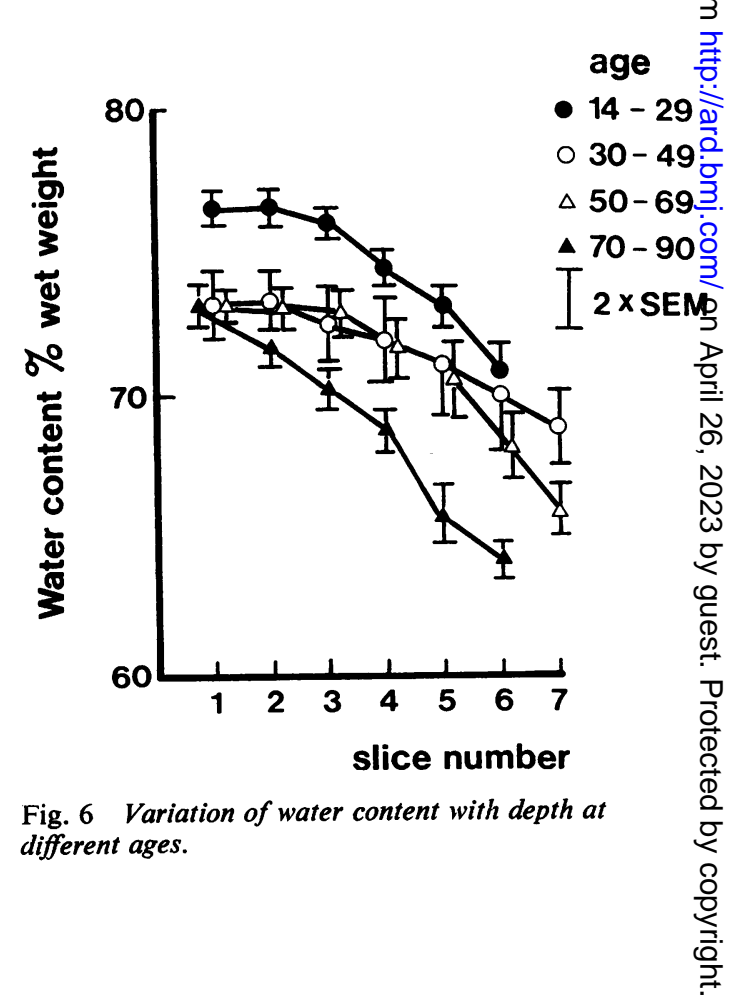


reduced throughout the cartilage with a greater age difference in the deep zones compared to the surface.

On a wet weight basis glycosaminoglycan content increased with age up to the age group 50-69 years. The increase was most marked in the middle and deep zones of the cartilage (Fig. 7). The oldest age group, 70-90 years, showed a slightly lower glycosaminoglycan content in the deep zones. The total glycosaminoglycan content at the surface was not significantly different in the four age ranges. Chondroitin sulphate content was almost uniform throughout the depth of the cartilage and did not vary with age (Fig. 8). In contrast, there was a wide variation in the profile of keratan sulphate content with depth in cartilage at different ages (Fig. 9). Keratan sulphate content was low in the youngest age group (14-29 years) and there was only a small

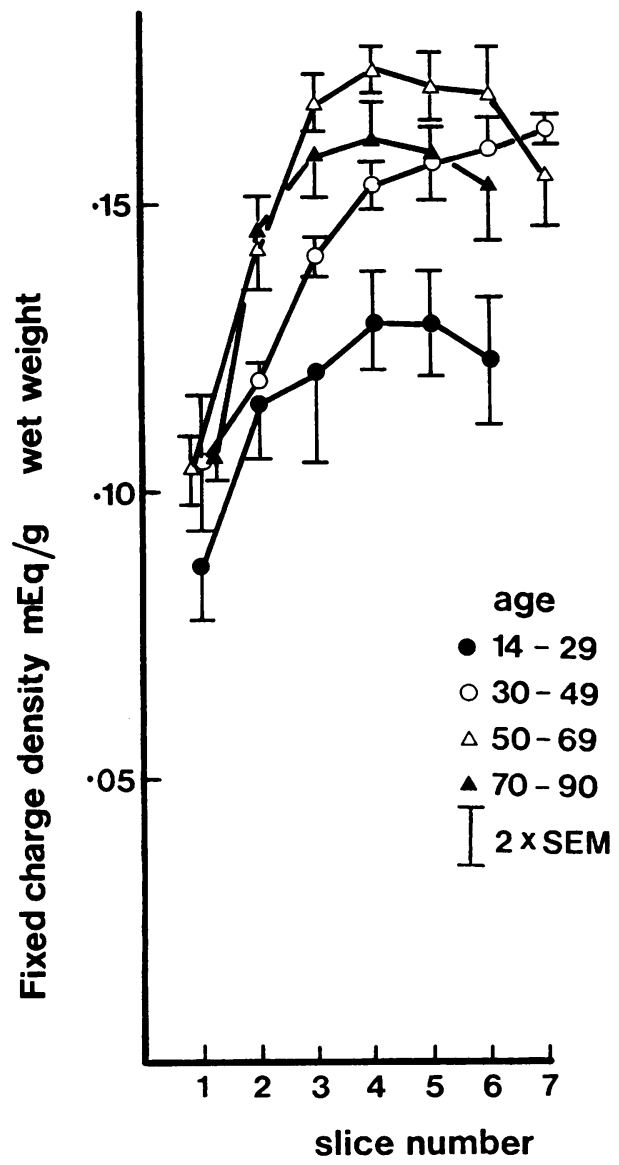

Fig. 7 Variation of fixed charge density with depth at different ages. increase with depth. In the next group (30-49 years) there was a marked increase in keratan sulphate especially in the deep zones. In the oldest groups keratan sulphate content was increased in both the deep and the surface layers and was present in almost equimolar concentrations with chondroitin sulphate.

On a wet weight basis collagen content showed little variation with depth or age. However, on a dry basis collagen content was greatest at the suriace and decreased with depth. This depth variation increased with age (Fig. 10).

\section{Discussion}

Fixed charge density shows an excellent correlation with chemical analyses over a wide range of values (Venn and Maroudas, 1977), although in degenerate samples with a low glycosaminoglycan and high collagen content fixed charge density should be measured using a solution containing both ${ }^{22} \mathrm{Na}$ and ${ }^{36} \mathrm{Cl}$, and the uronic acid content should be reduced by a factor related to the collagen content (Venn and Maroudas, 1977). In practice this is

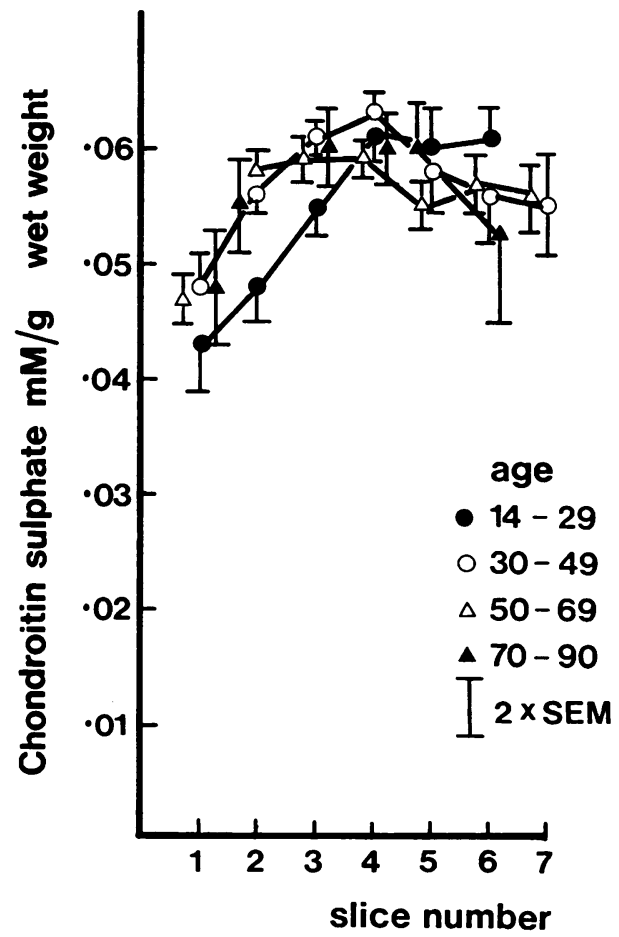

Fig. 8 Variation of chondroitin sulphate content with depth at different ages. 


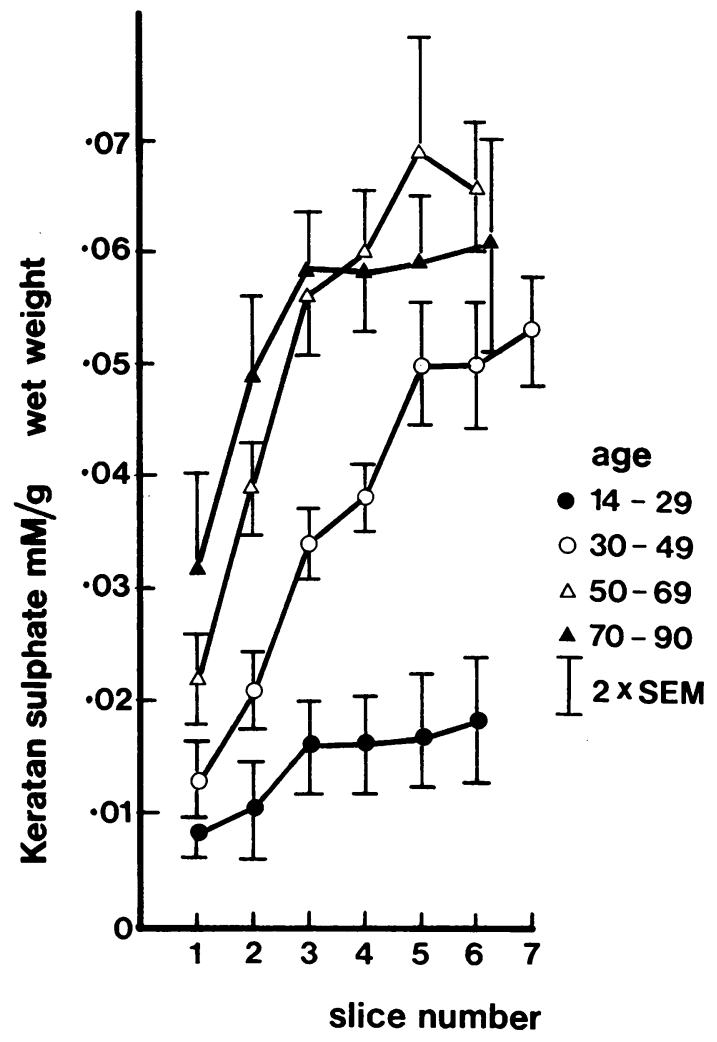

Fig. 9 Variation of keratan sulphate content with depth at different ages.

unnecessary for intact cartilage with a high glycosaminoglycan content. Since fixed charge density measures the total net negative charge in the tissue it is liable to overestimate the glycosaminoglycan content if there is a significant concentration of other negatively charged molecules, or to underestimate if any net positively charged molecules are present. In practice such difficulties rarely arise since negatively charged constituents such as sialic acid are present in small amounts compared to the glycosaminoglycan content $(<0.5 \%$ of the dry weight in calf articular cartilage (Campo and Tourtellotte, 1967)) and the main protein constituents of cartilage have no net charge (Freeman and Maroudas, 1975). A source of error in the chemical analyses is that hexosamine-containing glycoproteins give a positive result on hexosamine analysis and thus an overestimate of keratan sulphate content. However the hexosamine content of the structural glycoproteins is low ( $<3 \%$ in pig aorta (Robert et al., 1970)) and would not contribute significantly to the hexosamine values unless large amounts of glycoprotein were

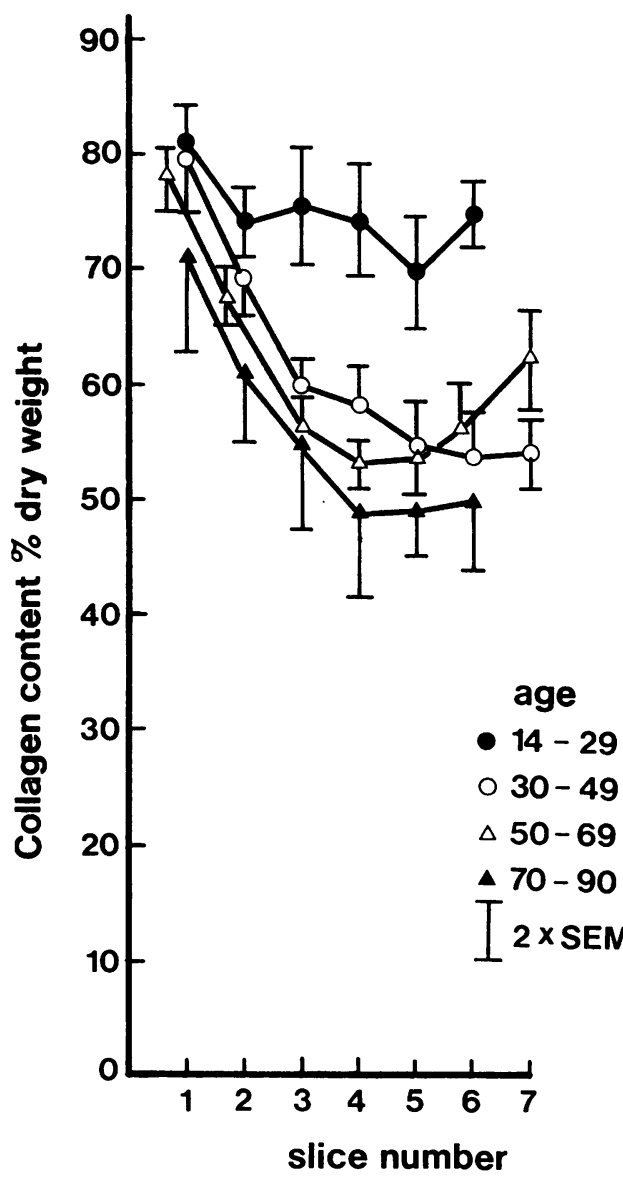

Fig. 10 V'ariation of collagen content with depth at different ages.

present. The glycoprotein content of extracted proteoglycans does however increase with age (e.g. Rosenberg et al., 1965; Bayliss, 1976) and this may contribute to part of the estimated increase keratan sulphate with age.

This study has shown that the composition of adult articular cartilage does alter with age, although the changes are small in comparison to those which occur during development. Probably the most striking changes are the decrease in water conten the decrease in collagen content on a dry basis, and the increase in noncollagenous material. Part of thos noncollagenous material may consist of minerât deposits, although there is also an increase in the protein component of the proteoglycans with age (Rosenberg et al., 1965; Bayliss, 1976).

The surface zone of articular cartilage show fewer age changes than the deeper layers whese 
glycosaminoglycan, water, and collagen contents varied considerably with age. This may be of physiological significance in that it is the surface layer which is in contact with the opposite articulating surface and any changes would affect the functioning of the joint.

The results of the present study in general agree with the results reported for the variations in the composition of extracted proteoglycans with age. For example, Strider et al., (1976) and Bayliss (1976) observed a decrease in the proportion of chondroitin sulphate and an increase in keratan sulphate, sialic acid, and protein in extracted proteoglycans with age.

The present study clearly indicates that agerelated biochemical changes do occur in mature cartilage. It is important that the normal biochemical changes which occur during the aging of cartilage should be well understood and documented, in order that the data may act as a baseline against which degenerative changes can be compared. In the early work on cartilage biochemistry changes in composition indicative of degenerative changes were in some cases confused with age changes. This was partly due to the use of pooled specimens in which there was an increasing area of fibrillation with age. It is now clear that the degenerative changes are quite distinct from the age-related changes which occur in intact cartilage. In osteoarthrotic cartilage the trend towards hydration and loss of glycosaminoglycans increasing with increasing degeneration (Venn and Maroudas, 1977) is the reverse of the normal trend with age in intact cartilage.

I am grateful to the MRC for financial help.

\section{References}

Anderson, C. E., Ludoweig, J., Harper, H. A., and Engelman, E. P. (1964). The composition of the organic component of human articular cartilage. Journal of Bone and Joint Surgery, 46A, 1176-1183.

Bayliss, M. (1976). A study of the biochemical mechanisms involved in human osteoarthritic cartilage. Thesis, University of London.

Bitter, T., and Muir, H. (1962). A modified uronic acid carbazole reaction. Analytical Biochemistry, 4, 330-334.

Bjelle, A. O. (1974). Variations in content and composition of glycosaminoglycans within the lower femoral epiphysis of an adult. Scandinavian Journal of Rheumatology, 3, 81-88.

Bollett, A. J., and Nance, J. L. (1966). Biochemical findings in normal and osteoarthritic articular cartilage. II. Chondroitin sulphate concentration and chain length, water and ash content. Journal of Clinical Investigation, 45, 1170-1177.

Byers, P. D., Contepomi, C. A., and Farkas, T. A. (1970). A post-mortem study of the hip joint. Annals of the Rheumatic Diseases, 29, 15-31.

Campo, R. D., and Tourtellotte, C. D. (1967). The composition of bovine cartilage and bone. Biochimica et Biophysica Acta, 141, 614-624.
Collins, D. H., and Meachim, G. (1961). Sulphate $\left({ }^{35} \mathrm{SO}_{4}\right)$ fixation by human articular cartilage compared in the knee and shoulder joints. Annals of the Rheumatic Diseases, 20, 117-129.

Elson, L. A., and Morgan, W. T. J. (1933). A colorimetric method for determination of glucosamine and chondrosamine. Biochemical Journal, 27, 1824-1828.

Freeman, W. D. S., and Maroudas, A. (1975). Charged group behaviour in cartilage proteoglycans in relation to $\mathrm{pH}$. Annals of the Rheumatic Diseases, 34, Suppl. 2, 44-45.

Freeman, M. A. R., and Meachim, G. (1973). Ageing, degeneration and remodelling of articular cartilage. Adult Articular Cartilage, pp. 287-329. Ed. by M. A. R. Freeman. Pitman, London.

Grant, R. A. (1964). Estimation of hydroxyproline by autoanalyser. Journal of Clinical Pathology, 17, 685-689.

Hjertquist, S. O., and Lemperg, R. C. (1967). Studies of autologous diced costal cartilage transplant. III. With special regard to glycosaminoglycans, hydroxyproline, calcium and ${ }^{35} \mathrm{~S}$-sulphate incorporation in vitro after intramuscular implantation. Acta Societatis Medicorum Upsaliensis, 72, 173-183.

Hjertquist, S. O., and Lemperg, R. C. (1972). Identification and concentration of the glycosaminoglycans of human articular cartilage in relation to age and osteoarthritis. Calcified Tissue Research, 10, 223-237.

Hjertquist, S. O., and Wasteson, A. (1972). The molecular weight of chondroitin sulphate from articular cartilage. Effect of age and of osteoarthritis. Calcified Tissue Research, 10, 31-37.

Kaplan, D., and Meyer, K. (1959). Ageing of human cartilage. Nature, 183, 1267-1268.

Kempson, G. E. (1973). Mechanical properties of articular cartilage. Adult Articular Cartilage, pp. 171-227. Ed. by M. A. R. Freeman. Pitman, London.

Kuhn, R., and Leppelmann, H. J. (1957). Der Hexosamingehalt des Korpels in Abhängigkeit vom Lebensalter. Liebigs Annalen der Chemie, 607, 202-206.

Lemperg, R. C., Larssen, S. E., and Hjertquist, S. O. (1971). Distribution of water and glycosaminoglycans in different layers in relation to age. Calcified Tissue Research, 15, 237-243.

Lemperg, R. C., Larssen, S. E., and Hjertquist, S. O. (1974). The glycosaminoglycans of bovine articular cartilage. I. Concentration in different layers in relation to age. Calcified Tissue Research, 15, 237-243.

Maroudas, A. (1975). Biophysical chemistry of cartilagenous tissues with special reference to solute and fluid transport. Biorheology, 12, 233-248.

Maroudas, A., and Thomas, H. (1970). A simple physicochemical method for determining fixed anionic groups in connective tissue. Biochimica et Biophysica Acta, 215, 214-216.

Maroudas, A., Evans, H., and Almeida, L. (1973). Cartilage of the hip joint. Topographical variation of glycosaminoglycan content in normal and fibrillated tissue. Annals of the Rheumatic Diseases, 32, 1-9.

Miles, J. S., and Eichelberger, L. (1964). Biochemical studies of human cartilage during the ageing process. Journal of the American Geriatrics Society, 12, 1-20.

Robert, A. M., Robert, B., and Robert, L. (1970). Chemical and physical properties of structural glycoproteins. Chemistry and Molecular Biology of the Intercellular Matrix, pp. 237-242. Ed. by E. A. Balazs. Academic Press, London and New York.

Rosenberg, L., Johnson, B., and Schubert, M. (1965). Protein polysaccharides from human articular and costal cartilage. Journal of Clinical Investigation, 44, 1647-1656. 


\section{M. F. Venn}

Rüttner, J. R., Spycher, A. M., Werner, G., and Amado, R. (1974). Biochemical and morphological studies on the cartilage of the femoral head. Verhandlungen der Deutschen Gesellschaft für Pathologie, 58, 392-394.

Sokoloff, L. (1966). Elasticity of aging cartilage. Federation Proceedings, 25, 1089-1093.

Stegemann, H. (1958). Microbestimming von Hydroxyproline mit Chloramin-T und p. Dimethylaminobenzaldehyd. Zeitschrift für Physiologische Chemie, 311, 41-45.

Stockwell, R. A. (1970). Changes in the acid glycosaminoglycan content of the matrix of human cartilage. Annals of the Rheumatic Diseases, 29, 509-515.

Strider, W., Pal, S., Margolis, R., and Rosenburg, L. (1976). Changes with aging in the size and chemical composition of proteoglycan subunit and aggregate from normal dist femoral human articular cartilages. Transactions of the 22nd Annual Meeting, Orthopaedic Research Society, Nệ.

Orleans, p. 35 .
Venn, M., and Maroudas, A. (1977). Chemical composition and swelling of normal and osteoarthrotic femoral he cartilage. 1. Chemical composition. Annals of the Rheuma fec Diseases, 36, 121-129.

von Berlepsch, K. (1969). Two automated procedures for the determination of uronic acid in acid glycosaminoglycarg. Analytical Biochemistry, 27, 424-429.

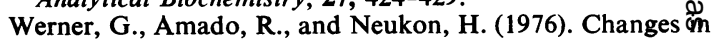
collagen content of human articular cartilage. European Federation of Connective Tissue Clubs Vth Meeting, Liège. 